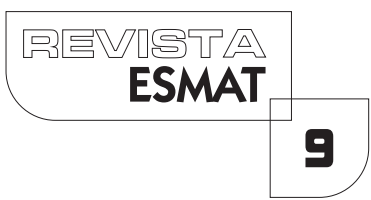

\title{
OS DIREITOS DA PERSONALIDADE E A LIBERDADE DE IMPRENSA: A CONDENAÇÃO ANTECIPADA DO ACUSADO ANTE A EXPOSIÇÃO MASSIFICADA DA MÍDIA
}

José Ribamar Mendes Júnior

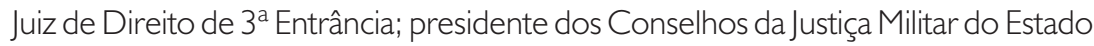
do Tocantins; $2^{\circ}$ vice-diretor da Escola Superior da Magistratura Tocantinense (ESMAT). Mestre em Direito Constitucional pela Faculdade de Direito Universidade de Lisboa e em Prestação Jurisdicional e Direitos Humanos pela Universidade Federal do Tocantins, ambas em parceria coma Esmat.E-mail:vrmendes@uol.com.br

\section{RESUMO}

O presente artigo tem como objetivo abordar o conflito existente entre os direitos da personalidade e a liberdade de expressão em sentido amplo, demonstrando a importância da ponderação de princípios como técnica de solução desse confronto. $\bigcirc$ estudo do tema justifica-se pela problemática da condenação moral antecipada de indivíduos acusados de crimes, fato que suprime destes direitos essenciais à dignidade humana e constitucionalmente protegidos, como a presunção de inocência, a honra, a imagem, entre outros. Demonstra-se como forma eficaz de solução de conflitos entre direitos fundamentais a ponderação de princípios.

PALAVRAS-CHAVE: Direitos da personalidade. Liberdade de expressão. Ponderação de princípios.

\section{ABSTRACT}

This article aims to address the conflict between personality rights and freedom of expression in a broad sense, demonstrating the importance of weighing of principles as a technique for solving this conflict. The study of the subject is justified by the anticipated problem of moral condemnation of individuals accused of crimes, suppressing them essential to human dignity and constitutionally protected rights such as the presumption of innocence, honor, image among others, demonstrating how effectively the solution of conflicts between fundamental rights weighting of principles.

KEYWORDS: Personality rights. Freedom of expression. Weighting of principles. 


\section{INTRODUÇÃO}

A Constituição da República Federativa Brasileira consagra o Estado Democrático de Direito e assegura a dignidade da pessoa humana como um de seus fundamentos, evitando a coisificação do ser humano. Também garante a liberdade em diversas modalidades, com desígnio de salvaguardar os direitos fundamentais, bem como os indivíduos de qualquer abuso advindo do Estado ou de outrem.

Nesse sentido, com o presente estudo, objetiva-se demonstrar a importância da ponderação de princípios como forma de solucionar o confronto entre a liberdade de expressão e os direitos da personalidade.

No Estado Democrático, a imprensa manifesta-se como detentora do papel fundamental de informar o povo. Apresenta-se também como instrumento de inclusão social a propagar ideologias e notícias, sendo imprescindível ao dia a dia do cidadão para minimizar os riscos de desmoralização do regime democrático.

O avanço tecnológico das mídias tem possibilitado o desenvolvimento da comunicação. Hoje, o espectador depara-se com as notícias em tempo real e, devido a essa evolução, há maior velocidade e facilidade de acesso à informação e às notícias dos fatos cotidianos. Dessarte, uma nova conduta da imprensa é essencial, sendo de suma relevância que a imprensa cumpra com seu papel social, pautada no compromisso com a verdade dos fatos e com a qualidade da comunicação e das notícias veiculadas.

Em contrapartida, a mídia viola os direitos da personalidade quando infere repercussão a caso concreto, pelos meios de comunicação em massa, não só acusando alguém do cometimento de um crime, mas condenando-o moral e antecipadamente pelo fato ocorrido. Essa espécie de veiculação possui consequências desastrosas, porque difunde um juízo de valor sobre o fato que, mesmo sob investigação, propaga opinião já concebida quanto à autoria ou inocência do indivíduo. Ou seja, a cobertura de um caso concreto, a partir de fontes não confíveis e sem a devida apuração do ocorrido, pode resultar em notícias meramente sensacionalistas e transgredir, irreversivelmente, o direito de imagem e de privacidade daquele que responde a um processo criminal.

Muitas vezes, a imprensa comporta-se tal como legítima empresa, a visar lucros sem se preocupar com sua verdadeira função social. Diante disso, indaga-se: Como exigir da mídia uma atuação pautada nos deveres de imparcialidade, transparência e de garantia dos direitos da privacidade e imagem dos indivíduos acusados do (possível) cometimento de crimes no País? 
A liberdade de expressão em caráter absoluto acaba por afrontar os direitos da personalidade e a dignidade da pessoa humana daquele que está sendo investigado. De outro modo, o controle abusivo da liberdade de expressão descaracteriza o estado democrático e também fere a dignidade humana. Por conseguinte, é necessária a intervenção jurisdicional, a fim de analisar o caso concreto e sopesar o valor que se entenda adequado aos direitos fundamentais em conflito.

Assim, com intuito de ver alcançado o objetivo proposto, aplica-se o método dedutivo, por meio da modalidade de pesquisa bibliográfica e qualitativa. Para tanto, estudam-se os conceitos de liberdade de expressão e direitos da personalidade, ambos como direitos fundamentais; ressalta-se a importância da mídia e do acesso à informação como essência do estado democrático; e, por fim, expõe-se a ponderação como técnica de solução da colisão de princípios.

\section{O PRINCÍPIO CONSTITUCIONAL DA LIBERDADE DE EXPRESSÃO}

A liberdade de expressão é direito de todos os cidadãos e garante aos indivíduos e às instituições a livre manifestação de opiniões, ideias e pensamentos, atividade intelectual, artística, científica, expressões não verbais, comportamental e de comunicação, além de caracterizar-se também pela exteriorização e acesso à informação.

De forma esclarecedora, o direito à liberdade de expressão é tratado constitucionalmente no inciso IV do artigo $5^{\circ}$, o qual estabelece ser "livre a manifestação do pensamento, sendo vedado o anonimato". O inciso IX desse mesmo dispositivo legal reitera, de forma mais específica, que "é livre a expressão da atividade intelectual, artística e de comunicação, independentemente de censura ou licença"; e o inciso XIV afirma, de igual modo, ser "assegurado a todos o acesso à informação e resguardado o sigilo da fonte, quando necessário ao exercício profissional". Ademais, dispõe o artigo 220, também da Carta Magna, que "a manifestação do pensamento, a criação, a expressão e a informação, sob qualquer forma, processo ou veículo não sofrerão qualquer restrição, observado o disposto nesta Constituição".

No direito pátrio, além da Constituição Federal, a liberdade de expressão é assegurada por outros instrumentos internacionais, ratificados pelo Brasil, como pela Declaração Universal dos Direitos Humanos. Este documento, em seu artigo XIX, dispõe que "toda pessoa tem direito à liberdade de opinião e 
expressão; este direito inclui a liberdade de, sem interferência, ter opiniões e de procurar, receber e transmitir informações e ideias por quaisquer meios e independentemente de fronteiras". Na Convenção Americana de Direitos Humanos (Pacto de San José da Costa Rica), em seu artigo 13, bem como no artigo 19 do Pacto Internacional sobre Direitos Civis e Políticos, também há essa previsão legal.

A liberdade é o poder de escolha do indivíduo, é o uso de agir segundo a sua própria vontade. Já a comunicação é importante processo de socialização, tendo em vista ser o homem um ser social, logo, é cotidiano as pessoas exporem suas opiniões e ideias. Todavia, embora a liberdade de expressão seja fundamental na construção de uma sociedade democrática, não se lhe pode imputar primazia absoluta, uma vez que, apesar da coibição à censura pela Carta Magna, o indivíduo ou instituição não ficam isentos da responsabilização penal ou civil.

Francisco Teixeira da Mota (20 I3, p. I I) define a liberdade de expressão como um valor coletivo da sociedade democrática e vai além, tratando-a como termômetro de tal regime:

A liberdade de expressão é não só um bem individual, mas também um valor
colectivo numa sociedade democrática, permitindo a livre circulação das mais
diversas informações e opiniões, [...]. A proibição de opiniões minoritárias,
incômodas ou mesmo ofensivas é um prejuízo não só para o cidadão que se viu
impedido de expressar livremente o seu pensamento como para toda
sociedade, que ficou privada do conhecimento dessa opinião ou informação
que, certa ou errada, contribuiria para uma sociedade mais democrática, porque
mais esclarecida. [...] A liberdade de expressão é não só uma componente
essencial dos regimes democráticos, como o grau de democraticidade de um
Estado pode ser razoavelmente aferido através do grau efectivo de liberdade de
expressão de que gozam os seus cidadãos.

Desta feita, sem a garantia da liberdade de expressão inexiste a democracia. Assim, "a liberdade de expressão é, então, enaltecida como instrumento para o funcionamento e preservação do sistema democrático (o pluralismo de opiniões é vital para a formação de vontade livre)" (MENDES; BRANCO, 20। 3 , p. 264).

Sempre que cerceada a liberdade de expressão de um indivíduo, limitando a propagação de informações e opiniões, são ameaçados outros direitos fundamentais e o próprio Estado Democrático. É importante salientar que, em sentido amplo, a liberdade de expressão compreende liberdade de pensamento, liberdade de imprensa e liberdade de informação, assegurando o 
direito de informar e de ser informado (MENDES; BRANCO, 20 I3).

Logo, é de total relevância destacar a função dos meios de comunicação e aprofundar nos conceitos de liberdade de imprensa e de informação, destacando sua importância ao interesse público.

\section{I A liberdade de imprensa e a importância dos meios de comunicação}

A importância da atuação da imprensa enquanto necessidade humana para garantir a livre informação deve ser vista por duas dimensões bem distintas, mas complementares. Em uma, atua a imprensa e seus profissionais, tendo em vista a perspectiva de o direito democrático fornecer à população informações claras e verdadeiras; e, em outra, há a perspectiva de busca da informação pela própria sociedade, ou direito de se informar. Constituem-se as duas na chamada liberdade de informação jornalística, sob o aspecto ativo e passivo informar e ser informado.

Diante da grande importância da função desempenhada pelos meios de imprensa, entende-se por fundamental a veracidade das informações repassadas à sociedade, pois se trata de consectário lógico para a credibilidade. Isso é essencial para o cumprimento do relevante papel social reservado aos meios de comunicação, qual seja, informar à sociedade e contribuir para o desenvolvimento de uma visão crítica dos fatos.

Os meios de comunicação de massa caracterizam-se por alcançar diversos receptores, por produzir grande quantidade de informação e celeridade de absorção, consequentemente, exercem função indispensável na disseminação de ideologias, pensamentos, notícias e, por isso, na composição da opinião pública. Sobre esse meio de comunicação, Mendel e Salomon (20 I I, p. I I) declaram que,

Na maioria dos países, a mídia de massa é o principal canal para a discussão popular sobre toda e qualquer matéria, sendo o direito à liberdade de expressão, por conseguinte, de primordial importância para os meios de comunicação. A Corte interamericana de Direitos Humanos declarou: 'É a mídia de massa que torna o exercício da liberdade de expressão uma realidade'.

Dessa forma, com base na liberdade de comunicação pela imprensa, é de suma importância que a mídia exerça sua função social, uma vez que a liberdade de expressão constitui pressuposto de todas as liberdades, bem como seja preservado o direito de ser informado e, ainda, "não apenas informado, mas bem informado mediante o recebimento de informação objetiva, precisa e 


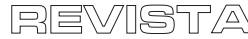

verdadeira, vedando-se distorções e manipulações" (STROPPA, 20 I 0, p. I 02).

Quando a mídia assim não o faz, acaba por afrontar a dignidade da pessoa humana, como foi o caso nacionalmente conhecido da Escola Base ', em que pessoas inocentes foram julgadas e condenadas por todos os meios de comunicação em massa, principalmente a televisiva, ocasionando condenação social antecipada.

Em caso de excesso em notícias divulgadas pelos veículos de comunicação social, a jurisprudência tem considerado indenizáveis os danos materiais e morais decorrentes desse abuso. $O$ direito à liberdade de informação possui dupla face: uma de defesa da imprensa contra o Estado e outra de defesa do cidadão contra os veículos de comunicação. E, ainda, uma perspectiva individual e coletiva - a primeira relacionada à garantia do direito à manifestação do pensamento -, e esta, preservando o direito de acesso à informação.

Desse modo, é axiomático entender que a condenação social advinda precocemente devido a uma exposição massificada nos meios de comunicação excede a condenação judicial, causando demasiados prejuízos. Ressalta-se que a Constituição da República Federativa Brasileira salvaguarda tanto a liberdade de imprensa como os direitos da personalidade e, portanto, esse espetáculo midiático precisa ser contido em face da eficácia dessas garantias, bem como da dignidade da pessoa humana.

\subsection{A liberdade de informação}

O direito à informação não é mais visto como simples liberdade de externar o pensamento, mas sim como direito fundamental de participação da sociedade, base para a democracia, com um tríplice alcance: o direito de informar, ser informado e se informar.

São pressupostos básicos da democracia a liberdade e a igualdade, os quais deixam de existir de fato quando ausente o conhecimento, a informação. Bobbio e Viroli (2008, p. 103) asseveram que

[...] o Estado brasileiro se traduz em um Estado Democrático de Direito, cujos princípios básicos derivados da liberdade constituem o seu alicerce, seu fundamento, irradiando seu valor sobre todas as normas jurídicas. Eis aí a importância do direito à informação, revelação do direito de liberdade a que o

'Disponível em: <http://stj.jusbrasil.com.br/jurisprudencia/249|4107/recurso-especial-resp| 2 | 5294-sp-20 | 0-0 | 775 | 7-0-stj/inteiro-teor-249|4 | 08 > . Acesso em 29 set. 20 I 5. 
povo receba informações [...] possibilitando, assim, que através da correta informação o ser humano alcance um nível satisfatório de conhecimento das coisas e fatos que o cercam enquanto membro da Comunidade [...].

O direito de informar é garantido pelo artigo 220 da Constituição Federal quando esta afirma não poder sofrer, a informação, nenhuma restrição. Assim, entendido como a liberdade de difundir informação, esse direito dá ao indivíduo a autonomia de veicular notícias, emitir opinião, comunicar fatos, e sua importância caracteriza-se pela formação da opinião pública.

Uma segunda conjuntura do tripé da liberdade de informação é o direito de ser informado, isto é, o direito de receber a informação. Nesse caso, não existe de forma expressa um dispositivo Constitucional, todavia é indiscutível, uma vez que não faria sentido resguardar a liberdade de expressão e a liberdade de informação, se não fosse tutelado o direito do receptor.

Por fim, no direito pátrio, a Carta Magna prevê a todos, no inciso XIV do artigo $5^{\circ}$, o acesso à informação (direito de se informar). Ou seja, o indivíduo tem a liberdade de buscar por informação, notícia, opinião, livremente, sem obstáculo.

A liberdade de expressão e os direitos da personalidade estão propensos a abalroarem-se e, havendo uma colisão, deve ser analisada a situação em concreto, por meio de ponderação, já que os princípios fundamentais possuem igual prestígio entre eles. Por tal motivo, serão estudados os direitos constitucionais da personalidade.

\section{OS DIREITOSDA PERSONALIDADE}

No século $X X$, com o positivismo jurídico, surge um direito geral da personalidade, pautado na autodeterminação, na dignidade da pessoa humana, fortalecendo o processo de positivação desses direitos em normas expressas.

A Constituição Cidadã de 1988 estabeleceu que:

Art. $5^{\circ}[\ldots] \bigvee$ - é assegurado o direito de resposta, proporcional ao agravo, além da indenização por dano material, moral ou à imagem; [...]

X - são invioláveis a intimidade, a vida privada, a honra e a imagem das pessoas, assegurado o direito a indenização pelo dano material ou moral decorrente de sua violação;

A personalidade, de acordo com Elimar Szaniawski (2005, p. 70), é um conjunto de atributos do próprio indivíduo, inerente à pessoa humana, pois "trata-se de um bem, no sentido jurídico, sendo o primeiro bem pertencente à 
pessoa, sua primeira utilidade. Através da personalidade, a pessoa poderá adquirir e defender os demais bens".

Os direitos da personalidade possuem duas características relevantes: são atribuídos a todo ser humano e oponíveis a toda a coletividade, bem como ao Estado; e consistem no fato de que sua violação nem sempre produz um prejuízo com repercussões econômicas e patrimoniais, ensejando formas variadas de reparação, como o direito de resposta.

Trata-se de direito amplo que engloba a integridade física, a vida, o próprio corpo, bem como envolve direitos à integridade moral, em que se inserem os direitos à honra, à liberdade, à vida privada, à intimidade, à imagem etc.

Segundo as lições de Pontes de Miranda (197I , p. 228), a honra, dividida em sua vertente interna (honra subjetiva) e externa (honra objetiva), encerra-se na dignidade pessoal, na consciência e no sentimento de ser digno. Seu conceito mostra-se demasiadamente subjetivo, motivo pelo qual o Superior Tribunal de Justiça, no julgamento do Resp 270.730/RJ, sedimentou entendimento a respeito do tema:

A alma de cada um tem suas fragilidades próprias. Por isso, a sábia doutrina concebeu uma divisão no conceito de honorabilidade: honra objetiva, a opinião social, moral profissional, religiosa que os outros têm sobre aquele indivíduo, e, honra subjetiva, a opinião que o indivíduo tem de si próprio. Uma vez vulnerado, por ato ilícito alheio, o limite valoração que exigimos de nós mesmos, surge o dever de compensar o sofrimento psíquico que o fato nos causar (MIRANDA, 197I, p. 228).

A intimidade consiste na qualidade do que é interior a cada ser humano. É o direito de estar só, de não ser perturbado em sua vida particular. A vida privada é o relacionamento de uma pessoa com seus familiares e amigos, o oposto da vida pública. É o direito de levar sua vida pessoal sem a intromissão de terceiros.

Maria Helena Diniz (2005, p. 135), quanto à privacidade, defende que a intimidade é uma espécie de privacidade, porquanto se atém a aspectos internos do cidadão; enquanto a privacidade em sentido amplo compreende também aqueles atos externos, cuja prática deve ser mantida, de acordo com a livre disposição da vontade do cidadão, em esfera restrita.

O direito à imagem é reconhecido pela Constituição Federal, de I 988, bem como pelo Código Civil, entendendo-se como projeção da personalidade física do indivíduo. É o "Direito da personalidade de autorizar a exposição ou a reprodução pública da imagem. [...] É, portanto, o direito de dispor da própria imagem, que é um bem jurídico essencial" (DINIZ, 2005, p. I2I). Com o 
desenvolvimento tecnológico e o progresso dos meios de comunicação, a imagem adquiriu grande relevância no contexto atual, tendo sido atribuído a ela valor, evoluído os meios de sua captação, reprodução e propagação.

Ademais, a Constituição Federal assegura ao ofendido, em seu direito de privacidade, a indenização por danos materiais e morais, conforme entendimento já consagrado na Súmula 37 do Superior Tribunal de Justiça.

Pelo exposto, nota-se que a disseminação de informação sem o devido cumprimento do meio de comunicação em massa de sua função social afronta os direitos da personalidade, garantidos constitucionalmente, bem como a dignidade da pessoa humana. Além disso, é possível concluir que os princípios constitucionais não possuem caráter absoluto e, portanto, na ocorrência de colisões entre eles, adota-se o princípio da proporcionalidade com a técnica de ponderação de valores.

\section{A COLISÃO DE DIREITOS FUNDAMENTAIS E A TÉCNICA DA PONDERAÇÃO DOS PRINCÍPIOS}

Por força do Princípio da Unidade da Constituição, não há hierarquia jurídica de normas constitucionais, principalmente quando se trata de direitos fundamentais, porque sustentam o mesmo status jurídico. Embora elencados constitucionalmente como direitos fundamentais, é possível a existência de conflito entre eles, quando o seu exercício por parte do titular colide com o exercício por parte de outro titular.

É de suma importância discorrer a respeito da distinção elucidada por Alexy (2012, p. 90) entre princípios e regras. O primeiro é definido por ele como mandamento de otimização, tratando-se, portanto, de permissões e proibições. Ou seja, os princípios possuem como característica, justamente, o fato de poderem ser cumpridos em graus distintos, a depender de condições fáticas, jurídicas e caso concreto.

Já as regras são normas a caracterizar determinado comportamento, e podem ser cumpridas, ou não, mas o devem ser de forma integral. Assim, "contêm [...] determinações no âmbito daquilo que é fática e juridicamente possível" (ALEXY, 20 I2, p. 9I). Por fim, conclui ser toda norma uma regra ou um princípio, tendo em vista que "ambos podem ser formulados por meio das expressões deônticas básicas do dever, da permissão e da proibição. Princípios são, tanto quanto as regras, razões para juízos concretos de dever-ser, ainda que de espécie muito diferente" (ALEXY, 20 I2, p. 87).

O autor também diferencia a denominação atribuída ao choque de normas, 
intitulado de "colisões entre princípios e conflitos entre regras" (ALEXY, 20 I2, p. 9I). Assim, no caso de conflito de regras, Alexy (20I2, p. 93) esclarece que a solução é a introdução de uma cláusula de exceção em uma das regras buscando sanar a incompatibilidade e, não sendo possível essa inclusão, deve, uma das regras, ser declarada inválida. Em igual sentido, Stroppa (20 I0, p. 199) estabelece três critérios para solucionar os conflitos entre regras, não aptos a orientar nos casos de colisão de princípios: cronológico (lei posterior derroga a anterior); hierárquico (lei superior derroga a inferior); da especialidade (lei especial derroga a lei geral).

Por sua vez, as colisões de princípios devem ser resolvidas de maneira distinta, caso de substancial relevância para o presente trabalho, tendo em vista seu objeto estar relacionado aos direitos da personalidade em colisão à liberdade de expressão (em sentido amplo), princípios fundamentais assegurados constitucionalmente no direito brasileiro.

Sérgio Ricardo de Souza (2008, p. 126) discorre sobre a ponderação como solução para dirimir a colisão de princípios, por meio de análise, pelo intérprete, dos valores orientadores de cada princípio no caso concreto:

A ponderação consiste na atividade desenvolvida pelo intérprete, que, ao se deparar com uma colisão entre princípios constitucionais, desenvolve uma análise sobre os valores que inspiram cada um daqueles princípios, procurando identificar, no caso concreto, qual deles possui mais relevância, dispondo-se a afastar a aplicação do outro naquele caso, sacrificando-o, entretanto, nos limites do extremamente necessário e mesmo assim sem extirpá-lo do ordenamento, já que continua válido e aplicável a outras situações.

RobertAlexy (20 12, p. 93-94) esclarece:

Se dois princípios colidem - o que ocorre, por exemplo, quando algo é proibido de acordo com um princípio e, de acordo com o outro, permitido -, um dos princípios terá de ceder. Isso não significa, contudo, nem que o princípio cedente deva ser declarado inválido, nem que nele deverá ser introduzida uma cláusula de exceção. Na verdade, o que ocorre é que um dos princípios tem precedência em face do outro sob determinadas condições. Sob outras condições a questão da precedência pode ser resolvida de forma oposta. Isso é o que se quer dizer quando se afirma que, nos casos concretos, os princípios têm pesos diferentes e que os princípios com o maior peso têm precedência. Conflitos entre regras ocorrem na dimensão da validade, enquanto as colisões entre princípios - visto que só princípios válidos podem colidir -, ocorrem, para além dessa dimensão, na dimensão do peso. 
Assim, não se aplicam na colisão de princípios os mesmos critérios utilizados para dirimir os conflitos entre as regras, uma vez que, no caso da colisão, usa-se a dimensão do peso de cada princípio, da sua importância diante do caso concreto, decidindo, por meio de sopesamento de valores, qual prevalecerá diante da hipótese. Isso não significa que o outro preterido será excluído, tendo em vista poder prevalecer em um caso concreto diverso diante daquele. Desse modo, "o objetivo desse sopesamento é definir qual dos interesses - que abstratamente estão no mesmo nível - tem maior peso no caso concreto" (ALEXY, 2012, p. 95).

Ante a impossibilidade de aplicação das clássicas técnicas da hermenêutica, a ponderação de interesses se apresenta como uma técnica de solução de conflitos aplicada a casos complexos, quando a subsunção se mostra insuficiente, pois confere ao caso concreto, em que normas de mesma hierarquia indicam soluções diversas, um resultado mais controlado e racional.

De acordo com Alexy (20 I2), é necessário decidir qual interesse deve ceder, levando-se em consideração a configuração típica do caso e suas circunstâncias especiais. Uma descrição mais inequívoca de uma colisão entre princípios dificilmente seria possível. Duas normas levam, se isoladamente consideradas, a resultados contraditórios entre si. Nenhuma delas é inválida, ou tem primazia absoluta sobre a outra. $O$ caso concreto é fator determinante da forma como será decidida a precedência entre elas.

Nesse sentido, o ministro Gilmar Mendes (20।2, p. 85) afirma que

Tem-se, pois, autêntica colisão apenas quando um direito individual afeta diretamente o âmbito de proteção de outro direito individual. Em se tratando de direitos submetidos a reserva legal expressa, compete ao legislador traçar os limites adequados, de modo a assegurar o exercício pacífico de faculdades eventualmente conflitantes.

A ponderação deve ser sempre pautada na consolidação dos valores constitucionais supremos. Assim, possui como pedra basilar a dignidade da pessoa humana, uma vez que todos os direitos fundamentais são desdobramentos desse princípio. Segundo Daniel Sarmento (2000, p. I05), "a ponderação deve sempre se orientar no sentido da proteção e promoção do princípio da dignidade da pessoa humana, que condensa e sintetiza os valores fundamentais que esteiam a ordem constitucional vigente".

Em termos práticos, o ilustre ministro Luís Roberto Barroso ${ }^{2}$ elenca alguns parâmetros constitucionais para a ponderação na hipótese de colisão entre direitos fundamentais, expostos a seguir. 
I. A veracidade do fato - a informação que goza de proteção constitucional é a informação verdadeira. A divulgação deliberada de uma notícia falsa, em detrimento do direito da personalidade de outrem, não constitui direito fundamental do emissor. Os veículos de comunicação têm o dever de apurar, com boa-fé e dentro de critérios de razoabilidade, a correção do fato ao qual darão publicidade. $O$ ministro ressalta que não se trata de uma verdade objetiva, mas subjetiva, subordinada a um juízo de plausibilidade e ao ponto de observação de quem a divulga. Para haver responsabilidade, é necessário haver clara negligência na apuração do fato ou dolo na difusão da falsidade.

2. Licitude do meio empregado na obtenção da informação - o conhecimento acerca do fato que se pretende divulgar, quando disponível em arquivos públicos, obtido por meios regulares e lícitos torna-se público e, portanto, não afeta a intimidade, a vida privada, a honra ou a imagem dos envolvidos. A Constituição, da mesma forma que veda a utilização, em juízo, de provas obtidas por meios ilícitos, também interdita a divulgação de notícias às quais se teve acesso mediante cometimento de um crime.

3. Personalidade pública ou estritamente privada da pessoa objeto da notícia - as pessoas que ocupam cargos públicos têm o seu direito de privacidade tutelado em intensidade mais branda. $\bigcirc$ controle do poder governamental e a prevenção contra a censura ampliam o grau legítimo de ingerência na esfera pessoal da conduta dos agentes públicos. Já as pessoas que não têm vida pública ou notoriedade desfrutam de uma tutela mais ampla de sua privacidade.

4. Local do fato - o ministro entende que os fatos ocorridos em local reservado têm proteção mais ampla do que os acontecidos em locais públicos. Eventos ocorridos no interior do domićlio de uma pessoa, como regra, não são passíveis de divulgação contra a vontade dos envolvidos. Mas, se ocorrerem na rua, em praça pública ou mesmo em lugar de acesso ao público, a princípio, são fatos noticiáveis.

5. Natureza do fato - existem fatos que são notícia, independentemente

²BARROSO, Luiz Roberto. Colisão entre liberdade de expressão e direitos da personalidade. Critérios de ponderação. Interpretação adequada do Código Civil e da Lei de Imprensa. Disponível em: <http://www.migalhas.com.br/arquivo_artigo/art_03-10-01.htm>. Acesso em 1०ago. 2014. 
dos personagens envolvidos. Acontecimentos da natureza, acidentes, assim como crimes em geral são passíveis de divulgação por seus evidentes interesses jornalísticos, ainda quando exponham a intimidade, a honra ou a imagem de pessoas neles envolvidos.

6. Existência de interesse público na divulgação em tese - 0 interesse público na divulgação de qualquer fato verdadeiro se presume como regra geral. A sociedade moderna gravita em torno da notícia, da informação, do conhecimento e de ideias. Sua livre circulação, portanto, é da essência do sistema democrático e do modelo de sociedade aberta e pluralista que se pretende preservar e ampliar. Caberá ao interessado na não divulgação demonstrar que, em determinada hipótese, existe um interesse privado excepcional que sobrepuja o interesse público residente na própria liberdade de expressão e de informação.

7. Existência de interesse público na divulgação de fatos relacionados com a atuação de órgãos públicos - esclarece que a regra é que toda a atuação do Poder Público, em qualquer de suas esferas, seja pública, o que inclui naturalmente a prestação jurisdicional. A publicidade, como é corrente, consiste no mecanismo pelo qual será possível ao povo controlar a atuação dos agentes que afinal praticam atos em seu nome.

8. Preferência por sanções a posteriori, que não envolvam a proibição prévia da divulgação - por fim, conforme Barroso, o uso abusivo da liberdade de expressão e de informação pode ser reparado por mecanismos diversos, que incluem a retificação, a retratação, o direito de resposta e a responsabilização, civil ou penal, e a interdição da divulgação. Somente em hipóteses extremas se deverá utilizar a última possibilidade. Nas questões envolvendo honra e imagem, por exemplo, como regra geral, será possível obter reparação satisfatória após a divulgação, pelo desmentido - por retificação, retratação ou direito de resposta - e por eventual reparação do dano, quando seja o caso. Já nos casos de violação da privacidade (intimidade ou vida privada), a simples divulgação poderá causar o mal de um modo irreparável.

Ademais, na prática, observa-se que a técnica da ponderação é aplicada a diversos casos concretos em que direitos fundamentais são claramente conflituosos. Nesse sentido, como exemplo, cita-se o REsp 895453 RS do ST $]^{3}$ eAPC 20 I 001 I 0825807 DF, do TJDF ${ }^{4}$.

Portanto, levando-se em consideração os fatores supramencionados, diante do caso concreto, deve o intérprete ponderar os valores atribuídos a cada princípio de modo que um prevalecerá diante do outro. Ou seja, esse 
sopesamento poderá prezar pelos direitos da personalidade, que são originários da dignidade da pessoa humana, ou, ainda, pela liberdade de expressão (em sentido amplo), desde que desempenhada conforme assegurado na Constituição, obedecendo à sua função social e possibilitando a construção de opinião pública e disseminação de ideias e ideologia, de modo a concretizar, de forma harmoniosa, a liberdade e a igualdade, sustentáculos do Estado Democrático de Direito.

\section{CONCLUSÃO}

O Estado democrático é consagrado no Brasil por meio da Constituição Federal e tem como um de seus fundamentos a dignidade da pessoa humana, princípio que corrobora para harmonização de todo o ordenamento jurídico. Esse Estado possui como alicerce a liberdade e a igualdade, impossibilitando, portanto, a coisificação do ser humano, determinando e salvaguardando outros direitos fundamentais.

Desse modo, a relação da dignidade da pessoa humana com a liberdade permite ao indivíduo exercer de forma absoluta seus direitos existenciais. Outrossim, a concepção de direitos da personalidade associa-se de igual modo à dignidade, porquanto constituem valores peculiares à essência da pessoa humana e substanciais à preservação da vida, imagem, honra e privacidade. Entretanto, tais direitos não são considerados absolutos, assim, em casos de conflitos entre eles, deve prevalecer o que mais seja adequado ao caso concreto, a fim de manter a coesão do Estado Democrático de Direito.

De outro modo, a liberdade de expressão é a essência de uma série de liberdades e direitos, sendo de máxima importância para uma sociedade democrática e, também, fundamental para o desenvolvimento e a garantia da dignidade da pessoa humana. Todavia, não se lhe pode imputar primazia absoluta. Assim, havendo algum tipo de abuso por indivíduos ou instituição, estes não ficam isentos da responsabilização penal ou civil, ou, ainda, de uma reparação como o direito de resposta.

${ }^{3}$ STJ. REsp 895453 RS, Rel. Min. CASTRO MEIRA. Segunda Turma, Julg. 12/I2/2006, DJ 2/2/2007.

${ }^{4}$ TJDF. APC 20I00II0825807 DF. Rel. Des. ANTONINHO LOPES, 4 ${ }^{\text {a }}$ Turma Cível, Julg. |8/6/20|4, DJe 20/8/20|4. 
É imprescindível que a mídia cumpra com seu papel social, transmitindo as informações diárias com ética, clareza, neutralidade, compromisso com a veracidade dos fatos e com a credibilidade da comunicação e das notícias veiculadas. Quando assim não o faz, afronta a dignidade da pessoa humana, tendo em vista seu poder de construir opiniões públicas e persuadir de forma a idealizar ou devastar o prestígio de uma pessoa.

Por serem princípios fundamentais, tanto a liberdade de expressão como os direitos da personalidade possuem igual prestígio e, portanto, deve ser analisado o caso em concreto de tal colisão por meio da ponderação de valores.

Os direitos da personalidade, intrínsecos a cada indivíduo, são protegidos constitucionalmente e por tratados internacionais. Esses direitos foram examinados no presente trabalho pelo viés dos direitos à intimidade e à vida privada, à honra e à imagem desses acusados explorados de forma abusiva pela imprensa nacional, fato que influencia na possível condenação judicial e, até mesmo, condena-os moralmente de forma antecipada.

Percebe-se a existência de conflito entre direitos fundamentais em que colide o exercício do direito por parte de um titular - direito à liberdade de expressão dos meios de comunicação, bem como o direito de se informar da sociedade -, com o exercício por parte de outro titular - pessoa humana que tem seus direitos da personalidade afrontados.

Nesse sentido, é necessário assentar qual o interesse que deve ceder, levando-se em consideração a configuração típica do caso e suas circunstâncias especiais. Para tanto, aplica-se a técnica de ponderação de valores, sopesando os princípios, a preservar o máximo factível de cada um desses em conflito.

\section{REFERÊNCIAS}

ALEXY, Robert. Teoria dos direitos fundamentais: tradução de Virgílio Afonso da Silva. 2. ed. São Paulo: Malheiros, 2012.

BARROSO, Luís Roberto. Colisão entre liberdade de expressão e direitos da personalidade. Critérios de ponderação. Interpretação adequada do Código Civil e da Lei de Imprensa. Disponível em: $<$ http://www.migalhas.com.br/arquivo_artigo/art_03-10-01.htm>. Acesso em $1^{\circ}$ ago. 2014.

BOBBIO, Norberto; VIROLI, Maurício. Diálogo em torno da República: os grandes temas da política e da cidadania, 2002. In: SOUZA, Sérgio Ricardo de. 
Controle judicial dos limites constitucionais à liberdade de imprensa. Rio de Janeiro: Lumen Juris, 2008.

BRASIL. Constituição da República Federativa do Brasil de 1988. Brasília, DF. D i s p o níve I e $\mathrm{m}$ : <http://www.planalto.gov.br/ccivil_03/constituicao/Constituicao.htm>. Acesso em 31 mar. 2014.

. Superior Tribunal de Justiça. STJ. REsp 895453 RS, Rel. Min. CASTRO MEIRA. Segunda Turma, Julg. I2/I2/2006, DJ 2/2/2007.

. Superior Tribunal de Justiça. STJ. REsp: I2 I 5294 SP. 20 I 0/0 I775 I70, Relator: Ministro RICARDO VILLAS BÔAS CUEVA, Data de Julgamento: 17/I2/20 I3, T3 - TERCEIRA TURMA, Data de Publicação: DJe I I/2/20 I 4.

. TJDF. APC 20100 I 10825807 DF. Rel. Des. ANTONINHO LOPES, 4a Turma Cível, Julg. I8/06/20 I4, DJe 20/8/20 I4.

DINIZ, Maria Helena. Teoria geral do direito civil. $22^{a}$ ed. v. I. São Paulo: Saraiva, 2005.

MENDEL, Toby; SALOMON, Eve. Liberdade de expressão e regulação da radiodifusão. Brasília: UNESCO, 201 I .

MENDES, Gilmar Ferreira. Direitos Fundamentais e controle de constitucionalidade: estudos de direito constitucional (Série EDB). $4^{\mathrm{a}}$ ed. ver. e ampl. São Paulo: Saraiva, 2012.

MENDES, Gilmar Ferreira; BRANCO, Paulo Gustavo Gonet. Curso de Direito Constitucional. 8. ed. rev. e atual. São Paulo: Saraiva, 2013.

MOTA, Francisco Teixeira da. A liberdade de expressão em tribunal. Lisboa: FFMS, 2013.

PONTES DE MIRANDA, Francisco Cavalcanti. Tratado de Direito Privado. Tomo VII. Rio de Janeiro: Borsoi, 1 97I.

SARMENTO, Daniel. A Ponderação de Interesses na Constituição Federal. 
Rio de Janeiro: Lúmen Júris, 2000.

SOUZA, Sérgio Ricardo de. Controle judicial dos limites constitucionais à liberdade de imprensa. Rio de Janeiro: Lumen Juris, 2008.

STROPPA, Tatiana. As dimensões constitucionais do direito de informação e o exercício da liberdade de informação jornalística. Belo Horizonte: Fórum, 2010.

STJ. Supremo Tribunal de Justiça. REsp 895453 RS, Rel. Min. CASTRO MEIRA. Segunda Turma, Julg. 12/12/2006, DJ 02/02/2007. Disponível em: <http://sti.jusbrasil.com.br/jurisprudencia/900888I/recurso-especial-resp895453-rs-2006-023004I-0/relatorio-e-voto-14|8098I >. Acesso em 29 set. 2015.

SZANIAWSKI, Elimar. Direitos de personalidade e sua tutela. $2^{\mathrm{a}}$ ed. ver. atual. e ampl. São Paulo: Revista dos Tribunais, 2005.

TJDF. Tribunal de Justiça do Distrito Federal. APC 20 I00 I I 0825807 DF. Rel. Des. ANTONINHO LOPES, $4^{\text {a }}$ Turma Cível, Julg. I8/06/20।4, DJe $20 / 08 / 20 / 4$. Disponívele m: <http://tjdf.jusbrasil.com.br/jurisprudencia/2363 I773/apelacao-civel-apc20 I 00 I I 0825807-df-20 I 00 I I 0825807apc-tjdf> . Acesso em 29 set. 20 I 5. 
